\title{
The Effect of Feedback from Pupil to Teacher on Assessment for Leaning and Visible Learning: An Ethnographic Case Study in a Community School in England and the Outcome in a State High School in Queensland, Australia
}

\author{
Daniel Ndisang ${ }^{1,2}$ and Alan Benson ${ }^{1}$ \\ ${ }^{1}$ Department of Education, London Metropolitan University, 166-220 Holloway Road, London N7 8DB, UK \\ ${ }^{2}$ Faculty of Education, Queensland University of Technology, Victoria Park Road, QLD 4059, Australia \\ Correspondence should be addressed to Daniel Ndisang; ndisang@hotmail.com
}

Received 2 September 2013; Revised 25 December 2013; Accepted 25 December 2013; Published 27 February 2014

Academic Editor: Gwo-Jen Hwang

Copyright (C) 2014 D. Ndisang and A. Benson. This is an open access article distributed under the Creative Commons Attribution License, which permits unrestricted use, distribution, and reproduction in any medium, provided the original work is properly cited.

\begin{abstract}
This study shows that there is positive regulatory effect of feedback from pupils to teachers on Assessment for Learning (AfL), classroom proactiveness, and on visible and progressive learning but not on behaviour. This research finding further articulates feedback from pupil to teacher as a paradigm shift from the classical paradigm of feedback from teacher to pupil. Here, the emphasis is geared towards pupils understanding of objectives built from previous knowledge. These are then feedback onto the teachers by the pupils in the form of discrete loops of cues and questions, where they are with their learning. This therefore enables them to move to the next level of understanding, and thus acquired independence, which in turn is reflected by their success in both formative and summative assessments. This study therefore shows that when feedback from pupil to teacher is used in combination with teacher to pupil feedback, AfL is ameliorated and hence, visible and accelerated learning occurs in a gender, nor subject non-dependent manner.
\end{abstract}

\section{Introduction}

In many schools in England and Australia, pupils who provide feedback to teachers, for instance, by asking relevant questions during lessons and activities, are more proactive in class and learn and progress faster than those who do not provide feedback to teachers [1-4]. Moreover, pupils who effortlessly move to the next or higher attainment levels in these schools, do so frequently when there is a place for a dynamic feedback process-more so from the pupils to the teachers than from the teachers to the pupils [5]. Furthermore, it has been evidenced that such dynamic feedback process from pupils to teachers not only motivates pupils, but also creates a milieu where teaching and learning becomes visible, and progressive learning becomes frequent $[6,7]$. Nonetheless, the phenomenon why this is so is still poorly understood. As a consequence, therefore, there are no effective tools, if any, to quantify and/or measure such dynamic feedback process from pupil to teacher $[8,9]$. It is imperative therefore to understand this phenomenon and its association with progressive learning.

This study therefore aims not only to show how feedback from "pupil to teacher" ameliorates Assessment for Learning (AfL) and hence visible and progressive learning, but also to develop a tool to measure such dynamic feedback process. Such tool, not least may address pupil's ability to judge and condescend, when and were in their personal learning process is the right juncture and junction to provide cues via feedback to teachers. Notwithstanding that there are more than one cofounder that could moderate learning $[8,10]$, in this study, only one parameter as a function of visible learning would be examined, that is, feedback from "pupil to teacher." In turn, this would be evidenced by the level of attainment. Evidently, it has been shown recently that feedback is among 
the most powerful influences on achievement $[5,8]$, and as such when teachers seek or at least are open to feedback from pupils, as to what pupils know, what they understand, where they make errors, and when they have misconceptions [11]; then the teachers become the learner, and the pupils become their own teachers [8]. Thus, teaching and learning becomes synchronized and hence visible teaching and learning occurs $[6,8,12]$.

Accordingly, pupils who do not ask questions or are proactive in class should therefore be encouraged to do so, given that recent studies on pedagogical feedback and learning have evidenced that, besides the classical paradigm of feedback from "teacher to pupil", there is however a novel prevailing paradigm that strongly advocates the reciprocal $[5,8,13]$. Furthermore, recent observations have also show that teaching technique which favoured the novel paradigm often leads to outstanding results within four weeks of teaching in a state high school in Queensland, Australia. Indeed, pupils were motivated and parents were ringing the schools to give positive appraisal. However, what was the most interesting was the number of students who did not only passed their SAT, but also exceeded their predicted grades. Such overwhelming progress achieved, albeit in very short time, warrants a better understanding of "pupil to teacher" feedback and its association with attainment and progressive learning.

In most schools in England and Australia [1-4, 14], teachers are encouraged to use pedagogies based on constructivist ideologies such as those of Piaget [15], DeVries [16], and Porcaro [13]. As a consequence, most teaching staff adopts a "pupil-centred" approach in teaching and learning $[8,13]$. The intension here is that pupils by their own accord could have greater opportunity to learn new information by building upon the knowledge they already possess [4, $7,15,16]$. To facilitate this approac therefore, teachers are constantly reminded to assess the knowledge pupils have already acquired, in order to determine whether such new knowledge is what they (the teachers) have intended [3, 4, 17]. To do this, several schools including those in this study have therefore come up with a "no hands-up" policy [18]. This meant that, during lessons and activities, teachers could not ask random questions aimed to the entire class; instead they channel targeted and probing questions to specific pupils. However, there are some inherent flaws with this "no hands-up" policy [18]. For instance, some pupils are embarrassed when "picked" or targeted to be questioned overtly, notwithstanding that teachers usually did not exercise sufficient patience to purse and allow pupils to come up with the desired answers.

Nonetheless, in England, some of these schools have a rigorous Assessment for Learning (AfL) policy in place [18], supplemented by a robust Assessing of Pupils' Progress (APP) tracking grid based on the UK National Standards on AfL and APP [19]. Thus, it is envisaged that the effective used of the APP tool would enable teachers as per the Ofsted AfL [5] to: “. . judgements about their pupils attainment,... provides diagnostic information about the strengths and weaknesses of pupils,...promotes teaching that matches the pupils and supports the transfer of meaningful information at key transitional points" [5]. However, there is no mention of the pupil's "voice" or account about their own learning, or how to tell the teacher where they (the pupils) are with their understanding process. Even though, according to this Assessment Reform Group [12], AfL is "the process of seeking and interpreting evidence for use bylearners and their teachers, to decide where the learners are in their learning, where they need to go, and how best to get there" [12]. Nonetheless, one of the key objectives of AfL in England is to link classroom assessment reliably to National Curriculum levels, in order to track the learning progress of individual pupils and intervene accordingly $[3,20]$. It is envisaged that this would be the case with the new Australian National Curriculum [21].

Hence, for the learning process to be progressive, newer evidence (objectives or targets) built from previous understood ones needs to be attained by the learner $[13,16$, 22]. This evidence could come from the teacher to the learner (pupils) or from the pupils to the teacher, via a twoway process of feedback $[4,8,23]$. Interestingly, this is in concordance with Sadler [6] report as stated "...feedback needs to provide information specially relating to the task or process of learning that fills a gap between what is understood and what is aimed to be understood, which is an aspect of visible teaching and learning..." [6]. However, more often than not, in most schools, the stream of evidence via the feedback process from "the pupil to the teacher" has not fully been documented or exploited $[5,8]$, and so visible learning as a consequence of this type of feedback is poorly understood. Nonetheless, according to Hattie [8] "visible teaching and learning occurs...when there is feedback given and sought by teachers and students...most evidently, the student learning occur when the teachers become learners of their own teaching, and when students become their own teachers" [8, page 22]. In addition, Ofsted AfL [5] has indicated that outstanding learning indicator is when pupils have the opportunity to reflect on their own learning which is in concordance with Hattie [8] meta-cognition strategies.

Consequently, by reflecting on their own learning, learners become their own teacher, and this is in agreement with the work of Hattie [8] which articulated that "visible teaching and learning occurs...when students become their own teachers" [8, page 22]. Interestingly, the National Strategies [3] have also reported that "AfL is a natural, integral, and essential part of effective learning and teaching and is a key element of personalised learning. . .teachers and children continually to reflect on how learning is progressing, see where improvements can be made and identify the next steps to take" [3].

Thus, on the one hand, visible learning hinges highly on effective feedbacks, and on the other hand, it depends on the pedagogy. This therefore indicates that visible teaching and learning could be achieved by the use of any popular educational approaches such as instructism or constructivism [7]. It is therefore not surprising that, when visible learning occurs, the teacher sees it and knows it, the learners see it and know it, and also an observer sees it and knows it [8], as evidenced not least by the positive appraisals from parents and guardians regarding the accelerated learning attainment 
of their children in science and chemistry classes at a state high school in Queensland, Australia.

\section{Methodology}

The methodology of choice for this case report was based but not limited to the theoretical framework of Bourdieu and Wacquant [24] and Qualis research [25] approach to ethnography: in this wise, multiple methods of data collection including participant observation, individual interviews, and small target groups (nonrandomised controlled) were employed. Ethnography is a form of qualitative and/or mixed research which includes field study and case report, as in the study herein.

\subsection{Participants}

\subsubsection{Coeducation Secondary Schools in England, UK, and in Queensland, Australia}

The School in England. This study took place in a coeducation comprehensive community secondary school in Leamington, Warwickshire, England. The number of pupils in the school role as of May 2011 was just under 500 pupils between the ages of 11 and 18. The school has higher than average SEN and EAL (predominantly from Poland and Iberia). According to the latest Ofsted report [18], the school is considered as "a school smaller than average school that caters primarily for pupils who live nearby, albeit that more pupils join and leave the school than the national average" [18]. Although the Osfted report [18] stated that the school is well managed, it was however stated further that, the most able pupils are not always fully challenged or given enough chance to work independently [18] and indeed this is type of behaviour by the school which is not ubiquitous in the maths department, particularly when it comes to feedback form "pupil to teacher."

Pupils. This research predominately took place in coeducational secondary schools, so as to enable cofounders to be determined whether they are gender related or not. Pupils were selected for this study based on the criteria as mentioned in the Data and Collection Section below. In brief, there were 21 pupils in total in Year 7 set 3, of wish 12 pupils, 6 boys and 6 girls were selected for this study based on the criteria as mentioned in Section 2.2. Thus, the following pupils with anonymous names participated in the study: boys; James, Brandon, Krystain; Manni, Pedro, and Jason and girls; Brittany, Ana, Shona, Manjit, Kuri, and Courtesy.

Staff. Staff were selected on the premise that only those with in-depth knowledge of the school's AfL and APP policies, and especially well versed with that of the pupils in Year 7 set 3 pupils.

2.1.2. The School in Australia. A novel "pupil-centred" approach in teaching and learning (where pupils are encouraged to frequently provide feedback to teachers about their own learning) was used to accelerate learning in two classes in a state high school in Queensland, Australia.

Pupils. This novel paradigm of teaching was used to teach a Year 9 and a Year 11 class. There were 23 pupils in the Year 9 class, of which 15 were girls and 8 were boys. Whilst. for the Year 11 class, there were 8 pupils in total; 7 girls and a boy.

Staff. A mathematics and science teacher with sound understanding of the novel paradigm of teaching, which advocates that accelerated and progressive learning can be achieved, by simply encouraging pupils to frequently provide feedback to teachers about their own learning.

2.2. Data Collection. There are two phases of data collection employed during this study.

In Phase I, data was collated from the archival and current Assessment for Learning (AfL) and Assessing Pupils Progress (APP) databanks for the participating pupils in England. The data provides the working level of each pupil for each month, their predicted level for each month, and their attainment level for each month as judged by the monthly Summative Assessment Tests (SAT). This attainment level data was then pooled together for each participant and then compared with their respective estimated "pupil to teacher" feedback as judged by their class teachers and the other relevant teaching staff. The data was then analysed and the necessary correlations were made. Pupils were then categorised into two case groups.

In Phase II, feedback from "pupil to teacher" and other cofounders like class proactiveness and behaviour was measured in real time for each participating pupil. To do this, each pupil in both groups was observed and shadowed during entire maths lessons and activities for a set period of time. At the end of the period, the measured information was pooled and then compared with a structure standardised summative test. This standard test scored was equivalent to the pupil's maths attainment level at the end of the research study period. The data collected was recorded and analysed in accordance with the approach of Schatzman and Strauss [26] and Bourdieu and Wacquant [24].

2.3. Feedback Quantification and Measuring Criteria. Although there are more than one variable that could moderate learning, in this study, only one parameter as a function of visible learning has been examined, that is, feedback from "pupil to teacher." In this study, therefore, the main criteria assigned to measure feedback from "pupil to teacher" are simply the "frequency of relevant questions asked in maths lessons or activities." Thus, for a question to be deemed relevant, it must be related to a given set of learning objects, indicating that the person who asked the questions would have surmounted their current threshold of learning and understanding.

In this study, "pupil to teacher" feedback was quantified by assigning arbitral values between 1 and 4 to the frequency of relevant questions asked by a pupil to a teacher. That is, a maximum weight of 4 equates to "frequent asking of 
relevant questions;" a weight of 1 indicates "rare asking of relevant questions," while 0 is equated to those who do not ask questions at all. Using these criteria, participants were pooled into two case groups. Group A comprised pupils who give feedback to teachers, and Group B consisted of those pupils who rarely or do not give feedback to teachers. Similarly, arbitral values are used as equivalences to quantify the attainment levels from the maths AfL and APP databanks and standardised structured summative assessments. For instance, levels $3 c=1 ; 3 b=1.5 ; 3 a=1.75 ; 4 c=2 ; 4 b=2.5$; $4 \mathrm{a}=2.75 ; 5 \mathrm{c}=3 ; 5 \mathrm{~b}=3.5 ; 5 \mathrm{a}=3.75 ; 6 \mathrm{c}$ or above $=4$. However, such similar techniques could be used as a tool, not only to quantify and measure abstract cofounders like feedback, but also to quantify other types of scores or weight from different academic establishments as well as other abstract variables.

Thus, to show in the first instance (Phase I) whether "pupil to teacher" feedback has an effect on AfL as indicated by attainment levels, the mean attainment level was compared with the mean estimated feedback values of each participating pupil. However, in Phase II, to get a more accurate estimate of "pupil to teacher" feedback on the basis of the frequency of relevant questions asked during maths lessons and/or activities, and so confirm or annul any correlations made in Phase I, the same pupils in both categories as defined above were interviewed, observed, and shadowed during maths lessons and/or activities form mid-May to June, and their "pupil to teacher" feedback and other cofounders such as classroom behaviour and classwork proactiveness values measured in real time. The respective averages of each cofounder were then determined.

Thus, classwork proactiveness and behaviour were as feedback, measured and quantified by given arbitral values from 1 to 4 . That is, 4 is the best behaviour or completing all classwork correctly in time, and 1 is fair behaviour or to complete minimum classwork in time, while 0 is bad behaviour and rarely complete any classwork correctly in time. Finally, a standard summative test which covers the period of the study was given to the participants and their attainment levels determined. This was then used together with the classwork proactiveness and behaviour data to tabulate tables and generate curves for analysis and so determine the effect of feedback on progressive learning.

\section{Data Analysis}

3.1. Phase I Data Analysis. To show whether feedback from pupil to teacher has an effect on AfL and learning progress, the mean attainment level from January to mid-May and the SAT result in April were compared with the mean estimated feedback value during this period for each participating pupil as shown in Figure 1 and Table 1. To evaluate the effect of feedback on AfL and other cofounders, the bundle Microsoft Excel Student's $t$-test and ordinal regression analysis softwarewere used to analysethe coefficient of regression and the differences of the mean between variables. At all instance in this report, $P$ values of less than $0.05(P<0.05)$ with $95 \%$ confidence interval (CI) were used as the cut-off for statistical significance.
3.2. Phase II Data Analysis. To confirm the effect of feedback from "pupil to teacher" on attainment level and learning progress, a case study was carried out from mid-May to early June. Thence, participants were put into two case groups; Group A and Group B. In Group A, participant was selected on the basis that their equivalence frequency was judged in Phase I of the study to be greater than 1, and for those for Group B, it was judged to be less than 1. The participants were shadowed and observed during maths lessons and activities form mid-May to June, and the behaviour, classwork proactiveness, and feedback data were periodically collected and recorded during this period. At the end of this period, the respective averages were determined. A structured test was then given to the participants at the end of the study period and their attainment levels were determined. It was used together with the feedback, classwork proactiveness, and behaviour data to further tabulate tablesand generate curves to analyse the direct effect of feedback on progressive learning and so established whether such cofounder which regulates visible learning could be affected by gender.

\section{Results Findings}

4.1. Phase I Findings. In Phase I of this study, the attainment levels of 12 selected participants were obtained from the AfL and APP data. It was then compared with their respective estimated feedback values as explained in Section 3. The results show that pupils with higher feedback (pupil to teacher) values turn to be those with the highest attainment levels in class (Table 1(a)). Conversely, participants with lower feedback values (pupil to teacher) were those with the lowest attainment levels in class (Table 1(a)).

For instance, Brandon, Krystain, and Brittany recorded the highest estimated feedback value of 4 (which means that they frequently asked relevant questions pertaining to lesson objections during class task or activities). Indeed their attainment levels from January to mid-May as well as their SAT results were among the highest in class. In contrast Kiran, Manjot, and Courtesy recorded the lowest estimated feedback value. Interestingly, their attainment levels during the same period were amongst the lowest in the class. This result therefore indicates a relationship between feedback (from pupil to teacher) and the attainment level.

To better understand this relationship, the pupil's attainment levels were quantified and then compared with their respective estimated feedback values. To do this, arbitral values were assigned as equivalence to the attainment levels and the results tabulated as shown in Table 1 . Thus, levels $3 \mathrm{c}$ $=1 ; 3 \mathrm{~b}=1.5 ; 3 \mathrm{a}=1.75 ; 4 \mathrm{c}=2 ; 4 \mathrm{~b}=2.5 ; 4 \mathrm{a}=2.75 ; 5 \mathrm{c}=3$; $5 b=3.5 ; 5 a=3.75 ; 6 c$ or above $=4[3,27]$, and so the pupil's attainment levels and SAT results were converted into arbitral equivalences as shown below in Table 1(b).

The relationship between feedback and attainment can then be evaluated further using their equivalence values in Table 1(b). Thus, Figure 1 was generated to show clearly the effect of feedback from "pupil to teacher" on attainment levels. For instance, pupils with at least a feedback value of 3 were working on at least level $5 c$, while those with 


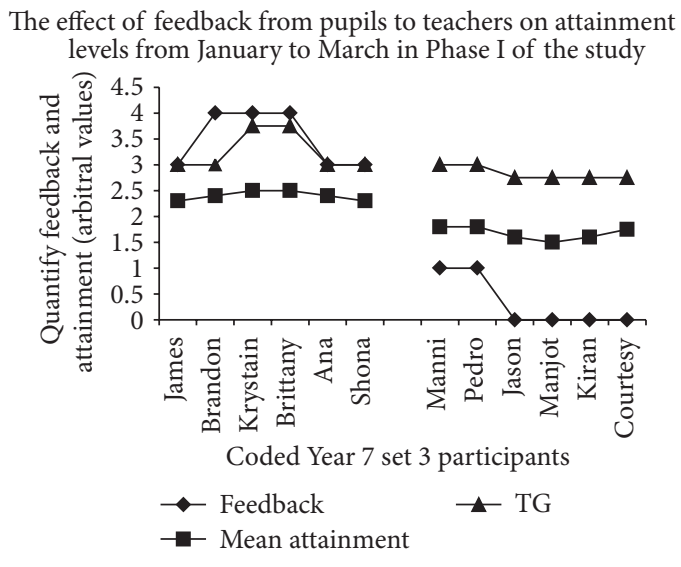

(A)

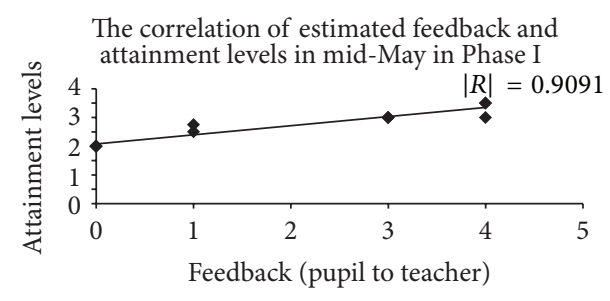

(B)
The effect of feedback from pupils to teachers on attainment

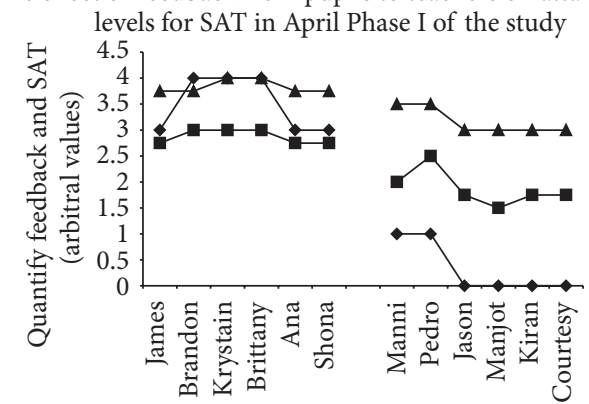

Coded Year 7 set 3 participants

$\rightarrow$ Feedback $\rightarrow$ PG

- SAT in April

(A)

The correlation of estimated feedback and attainment levels on the SAT results in April in Phase I

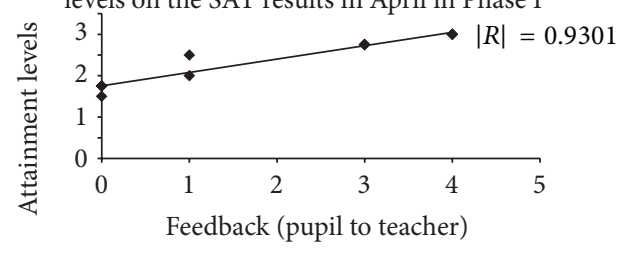

(B)

(a)

(b)

The effect of feedback from pupils to teachers on attainment

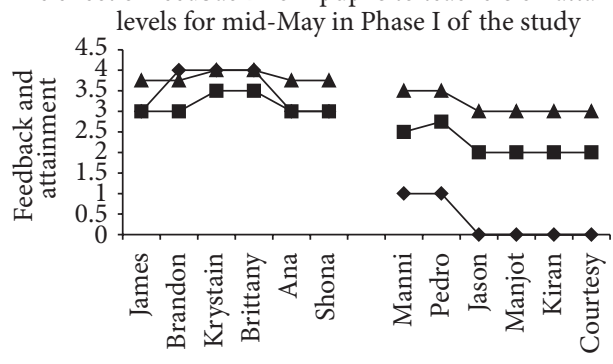

Coded Year 7 set 3 participants

$\multimap$ Feedback $\quad$ - PG

$\rightarrow$ Attainment

(A)

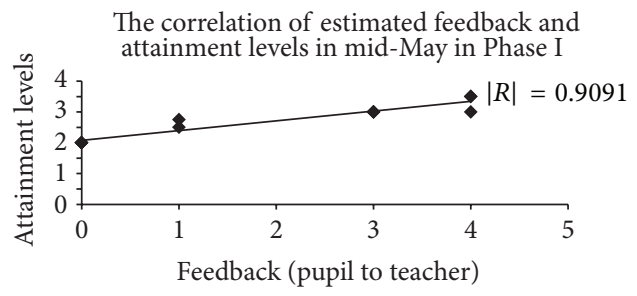

(B)

(c)

FIGURE 1: (a, A) shows the effect of feedback from pupils to teachers on attainment levels from January to March in Phase I of the study. (a, B) shows the correlation of the estimated feedback from pupils to teachers with the mean attainment levels from January to March in Phase I of the study. Note the teaching grade (TG). Also see Tables 1 and 2 for the quantification of attainment levels and feedback values. (b, A) shows the effect of feedback from pupils to teachers on the SAT results in April in Phase I of the study. (b, B) shows the correlation of the estimated feedback from pupils to teachers with the SAT results in April in Phase I of the study. Note the predicted grade (PG). Also see Tables 1 and 2 for the quantification of attainment levels and feedback values. (c, A) shows the effect of feedback from pupils to teachers on the attainment levels in mid-May. (c, B) shows the correlation of the estimated feedback from pupil to teacher on the attainment level in mid-May. 
TABLE 1: (a) The attainment Levels and estimated feedback values from pupils to teachers from January to mid-May in Year 7 set 3 in Phase I. (b) The estimated feedback values from pupil to teacher and the equivalence values of the attainment Levels from January to mid-May and the SAT in April for the participant of Year 7 set 3 in Phase I.

(a)

\begin{tabular}{|c|c|c|c|c|c|c|c|c|c|c|c|}
\hline $\begin{array}{l}\text { Case } \\
\text { groups }\end{array}$ & Sex & $\begin{array}{l}\text { Name } \\
\text { (coded) }\end{array}$ & $\begin{array}{l}\text { Feedback- } \\
\text { pupil } \\
\text { to } \\
\text { teacher* }\end{array}$ & Behaviour $^{\beta}$ & $\begin{array}{c}\text { Attainment } \\
\text { January }\end{array}$ & $\begin{array}{l}\text { Attainment } \\
\text { February }\end{array}$ & $\begin{array}{l}\text { Attainment } \\
\text { March }\end{array}$ & $\begin{array}{l}\text { SAT } \\
\text { test } \\
\text { April }\end{array}$ & $\begin{array}{l}\text { Attainment } \\
\text { mid-May }\end{array}$ & $\begin{array}{l}\text { Teaching } \\
\text { grade }\end{array}$ & $\begin{array}{l}\text { Predicted } \\
\text { grade }\end{array}$ \\
\hline \multirow{6}{*}{ Group A } & $\mathrm{M}$ & James & 3 & 4 & $4 c$ & $4 b$ & $4 b$ & $4 \mathrm{a}$ & $5 c$ & $5 c$ & $5 a$ \\
\hline & $\mathrm{M}$ & Brandon & 4 & 4 & $4 c$ & $4 \mathrm{~b}$ & $4 a$ & $5 c$ & $5 c$ & $5 c$ & $5 a$ \\
\hline & $\mathrm{M}$ & Krystain & 4 & 3 & $4 c$ & $4 a$ & $4 a$ & $5 c$ & $5 b$ & $5 a$ & $6 c$ \\
\hline & F & Brittany & 4 & 3 & $4 b$ & $4 \mathrm{~b}$ & $4 b$ & $5 c$ & $5 b$ & $5 a$ & $6 c$ \\
\hline & F & Ana & 3 & 4 & $4 c$ & $4 \mathrm{~b}$ & $4 a$ & $4 a$ & $5 c$ & $5 c$ & $5 a$ \\
\hline & $\mathrm{F}$ & Shona & 3 & 3 & $4 c$ & $4 \mathrm{~b}$ & $4 b$ & $4 \mathrm{a}$ & $5 c$ & $5 c$ & $5 b$ \\
\hline \multirow{6}{*}{ Group B } & $\mathrm{M}$ & Manni & 1 & 3 & $3 a$ & $3 a$ & $4 c$ & $4 \mathrm{~b}$ & $4 \mathrm{~b}$ & $5 c$ & $5 b$ \\
\hline & M & Pedro & 1 & 3 & $3 a$ & $3 a$ & $4 c$ & $4 \mathrm{~b}$ & $4 a$ & $5 c$ & $5 b$ \\
\hline & M & Jason & 0 & 4 & $3 b$ & $3 b$ & $4 c$ & $3 a$ & $4 c$ & $4 a$ & $5 c$ \\
\hline & $\mathrm{F}$ & Manjot & 0 & 4 & $3 b$ & $3 b$ & $3 b$ & $3 b$ & $4 c$ & $4 \mathrm{a}$ & $5 c$ \\
\hline & $\mathrm{F}$ & Kiran & 0 & 4 & $3 b$ & $3 b$ & $4 c$ & $3 a$ & $4 c$ & $4 a$ & $5 c$ \\
\hline & $\mathrm{F}$ & Courtesy & 0 & 4 & $3 a$ & $3 a$ & $3 a$ & $3 a$ & $4 c$ & $4 a$ & $5 c$ \\
\hline
\end{tabular}

* Estimated pupil to teacher Ffeedback values: (4 maximum, 1 minimum) frequency of feedback from pupil to teacher.

$\beta$ Class behaviour real values ( 4 best, 3 good, and 2 fair). Levels equivalence: $3 c=1 ; 3 b=1.5 ; 3 a=1.75 ; 4 c=2 ; 4 b=2.5 ; 4 a=2.75 ; 5 c=3 ; 5 b=3.5 ; 5 a=$ $3.75 ; 6 \mathrm{c}$ or above $=4$. See below.

(b)

\begin{tabular}{|c|c|c|c|c|c|c|c|c|c|}
\hline & Feedback & Behaviour & January & February & March & SAT April & mid-May & Teaching grade & Predicted grade \\
\hline James & 3 & 4 & 2 & 2.5 & 2.5 & 2.75 & 3 & 3 & 3.75 \\
\hline Brandon & 4 & 4 & 2 & 2.5 & 2.75 & 3 & 3 & 3 & 3.75 \\
\hline Krystain & 4 & 3 & 2 & 2.75 & 2.75 & 3 & 3.5 & 3.75 & 4 \\
\hline Brittany & 4 & 3 & 2.5 & 2.5 & 2.5 & 3 & 3.5 & 3.75 & 4 \\
\hline Ana & 3 & 4 & 2 & 2.5 & 2.75 & 2.75 & 3 & 3 & 3.75 \\
\hline Shona & 3 & 3 & 2 & 2.5 & 2.5 & 2.75 & 3 & 3 & 3.75 \\
\hline Manni & 1 & 3 & 1.75 & 1.75 & 2 & 2.5 & 2.5 & 3 & 3.5 \\
\hline Pedro & 1 & 3 & 1.75 & 1.75 & 2 & 2.5 & 2.75 & 3 & 3.5 \\
\hline Jason & 0 & 4 & 1.5 & 1.5 & 2 & 1.75 & 2 & 2.75 & 3 \\
\hline Manjot & 0 & 4 & 1.5 & 1.5 & 1.5 & 1.5 & 2 & 2.75 & 3 \\
\hline Kiran & 0 & 4 & 1.5 & 1.5 & 2 & 1.75 & 2 & 2.75 & 3 \\
\hline Courtesy & 0 & 4 & 1.75 & 1.75 & 1.75 & 1.75 & 2 & 2.75 & 3 \\
\hline
\end{tabular}

a feedback value of less than 1 could only work at level 4 (Figure 1(a), (A)). Moreover, the pupil's mean attainment levels from January to March increase as their feedback value increases (Figure 1(a), (B)), depicting a strong correlation with an absolute value of $R=0.96$, and $P<0.05$. This therefore suggests that feedback from pupil to teacher has a direct effect on the attainment level.

Interesting, similar relationship was also observed between feedback and the Summative Assessment Test (SAT) results in April (Figure 1(b), (A)), with a strong correlation of absolute $R=0.93, P<0.05$ (Figure 1(b), (B)). This suggests that feedback from pupils to teachers has not only a direct effect on the attainment levels, but also a direct effect on the SAT results. Nevertheless, the SAT result further shows that Pedro who has an estimated feedback value of "1" as Manni did relatively well in the SAT than Manni (Figure 1(b), (B)). This further suggests that there might be alternative intrinsic factors which might be regulating pupil's attainment other than feedback, notwithstanding that the estimated feedback values in mid-May correlate strongly with the attainment levels with an absolute $R=0.9, P<0.05$ (Figure 1(c), (B)). Moreover, as before, James, Brandon, Krystain, and Brittany higher levels of attainment parallel their high feedback values (Figure 1(c), (A)), while Manjot, Kiran, Courtesy, and Jason lower attainment levels parallel their lower feedback values (Figure 1(c), (A)), indicating that feedback from pupil to teacher directly regulates pupils' attainment levels and progressive learning. 
TABLE 2: Feedback from pupils to teachers and the equivalence values of the level of attainment and SAT results measured in mid-May and June in Phase II.

\begin{tabular}{|c|c|c|c|c|c|c|c|c|c|}
\hline $\begin{array}{l}\text { Case } \\
\text { groups }\end{array}$ & Sex & $\begin{array}{l}\text { Name } \\
\text { (coded) }\end{array}$ & $\begin{array}{c}\text { Feedback-pupil } \\
\text { to teacher }{ }^{\circledR}\end{array}$ & Behaviour $^{\beta}$ & Classwork & $\begin{array}{l}\text { Attainment } \\
\text { mid-May to } \\
\text { June }\end{array}$ & $\begin{array}{l}\text { SAT } \\
\text { in June }\end{array}$ & $\begin{array}{c}\text { Teaching } \\
\text { grade }\end{array}$ & Predicted grade \\
\hline \multirow{6}{*}{ Group A } & $\mathrm{M}$ & James & 3 & 4 & 4 & 3 & 3.5 & 3.5 & 3.75 \\
\hline & $\mathrm{M}$ & Brandon & 4 & 4 & 4 & 3 & 3.75 & 3.75 & 3.75 \\
\hline & $\mathrm{M}$ & Krystain & 4 & 3 & 4 & 3.5 & 3.75 & 3.75 & 4 \\
\hline & $\mathrm{F}$ & Brittany & 4 & 3 & 3 & 3.5 & 3.75 & 3.75 & 4 \\
\hline & $\mathrm{F}$ & Ana & 3 & 4 & 4 & 3 & 3.5 & 3.5 & 3.75 \\
\hline & $\mathrm{F}$ & Shona & 3 & 3 & 3 & 3 & 3.5 & 3.5 & 3.75 \\
\hline \multirow{6}{*}{ Group B } & M & Manni & 1 & 3 & 3 & 2 & 2.75 & 3 & 3.5 \\
\hline & M & Pedro & 1 & 3 & 3 & 2.75 & 3 & 3 & 3.5 \\
\hline & M & Jason & 0 & 4 & 3 & 2 & 2.5 & 2.75 & 3 \\
\hline & $\mathrm{F}$ & Manjot & 0 & 4 & 3 & 2 & 2 & 2.75 & 3 \\
\hline & $\mathrm{F}$ & Kiran & 0 & 4 & 3 & 2 & 2 & 2.75 & 3 \\
\hline & $\mathrm{F}$ & Courtesy & 0 & 4 & 3 & 2 & 2 & 2.75 & 3 \\
\hline
\end{tabular}

${ }^{\circledR}$ Estimated Pupil to Teacher Feedback values: (4 maximum, 1 minimum) frequency of Feedback from pupil to teacher.

${ }^{\beta}$ Class Behaviour are real value (4 best, 3 good, 2 fair).

4.2. Phase II Findings. To confirm this effect of feedback (from pupil to teacher) on the attainment level, a case-control study was carried out from mid-May to early June, of which feedback and other cofounders were measured in real time and not estimated as in Phase I. Thus, the participants from Phase I were put into two groups. Pupils in both groups were shadowed and observed during maths lessons and activities and their feedback, classwork pro-activeness, and behaviour data were measured and the result was used to tabulate Table 2.

These results suggest a profound effect of feedback (from pupils to teachers) not only on attainment levels, but also on the classwork proactiveness as well. Importantly, this confirms the findings in Phase I with similar feedback effect on attainment level. However, the result further shows not only that there is no significant difference between the estimated and measured feedback values (Figure 2(c)), but also that there is a statistically significant difference between the estimated and the measured attainment values $(P=$ 0.00016 ) (Figure 2(c)), with a strong correlation of absolute $|R|=0.88, P \leq 0.05$ (Figure $2(\mathrm{~d})$ ).

Consequently, to determine whether there is any significant difference between the experimental and the control feedback values, an ordinal regression analysis was further performed, and an absolute $|R|=0.92, P \leq 0.05$ was obtained (Figure 2(a)). Moreover, there is also a statistically significant difference between the experimental and control feedback mean values $(P=0.0000007)$ as well as that of the attainment values $(P=0.0002)$ (Figure $2(b))$. So, taking the results together confirms that feedback seems to have a real and direct effect on attainment levels (Figure 2) and other cofounders such as classwork proactiveness as shown in Figure 3, suggesting therefore that feedback directly regulates attainment levels and hence progressive and visible learning.
Moreover, as shown in Figure 4, this effect does not depend on gender. Furthermore, the data also reveals for the first time that behaviour does not affect the ability to provide feedback (Figure 3(c), (C)).

Interestingly, the results from mid-May to June therefore show that pupils in Group A with higher feedback values also have higher attainment levels, and some of these pupils exceeded their predicted target levels (Figure 3(a), (A)). In contrast, pupils in Group B (lower feedback values) also have the lowest attainment levels, and none of them exceed their predicted or target levels (Figure 1(b), (A)), notwithstanding that there is a strong correlation between attainment levels and feedback values during the mid-May-June period with an absolute $|R|=0.9$ (Figure 3(a), (B)), confirming again the findings in Phase I that feedback has a direct effect on the attainment levels and progressive learning. In addition, Group A which comprises those with the highest measured feedback values did quite well in the June SAT, as compared to Group B (pupils with the lowest feedback values) (Figure 3(b), (A)), with a strong correlation of absolute $|R|=$ 0.93, $P \leq 0.05$ (Figure 3(b), (B)), thereby confirming the earlier observations in Phase I that feedback from pupil to teacher seems to have not only a direct effect on attainment level, but also a direct effect on SAT results.

To determine whether feedback has an effect on classwork proactiveness and/or behaviour, the measured feedback data from mid-May to June was evaluated together with the measured classwork and behaviour data as already explained in Section 3. The result shows that, although some pupils in Group B were best behaved over this period, their feedback and attainment values were still very low in comparison to some of those in Group A, whose behaviour values were relatively lower than theirs, and yet have higher feedback and attainment values (Figure 3(c), (A)). Nonetheless, the two 


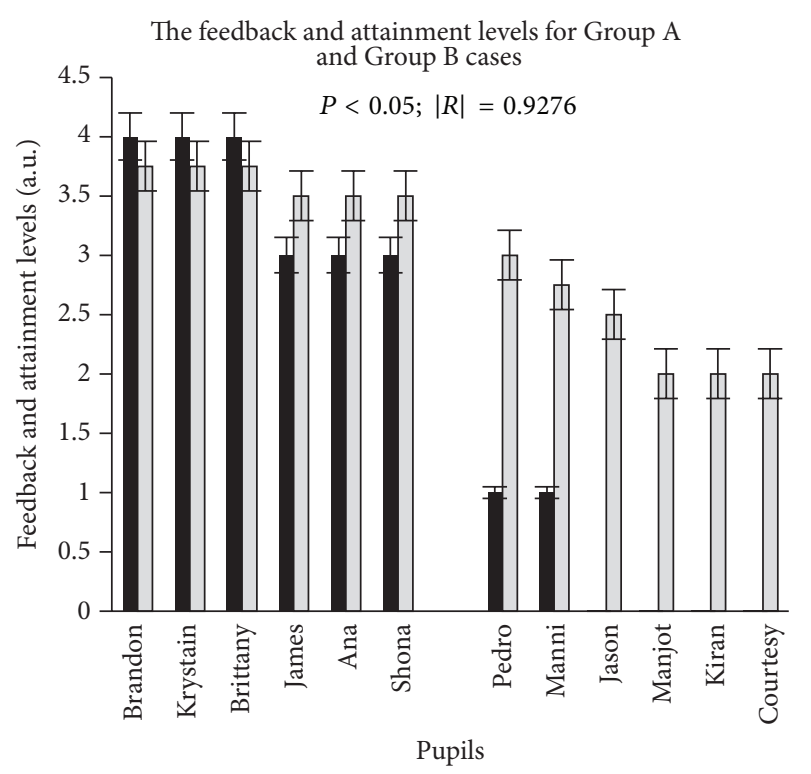

Feedback

Attainment

(a)

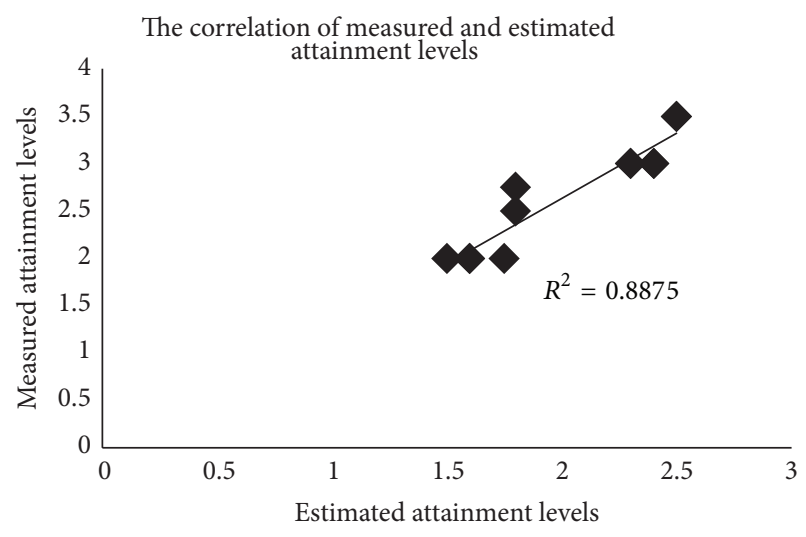

(c)

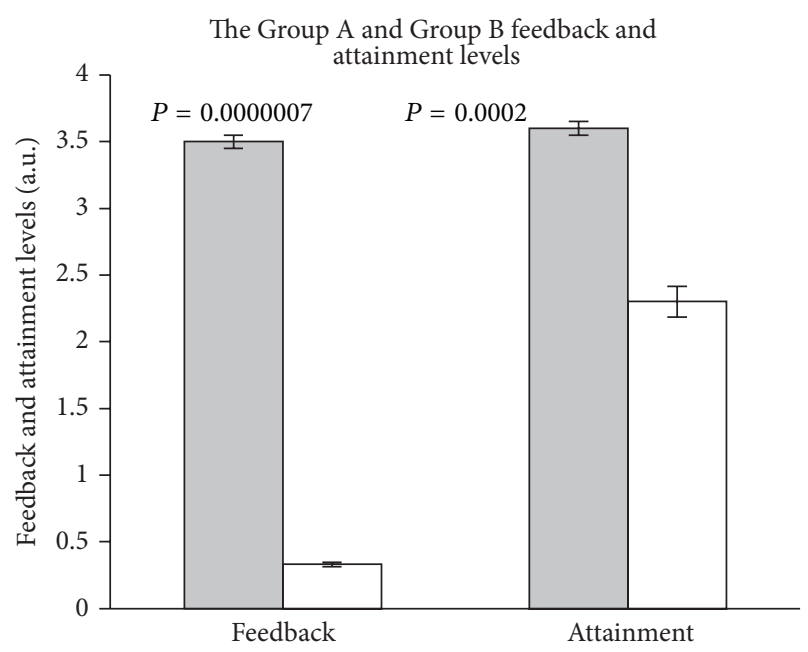

(b)

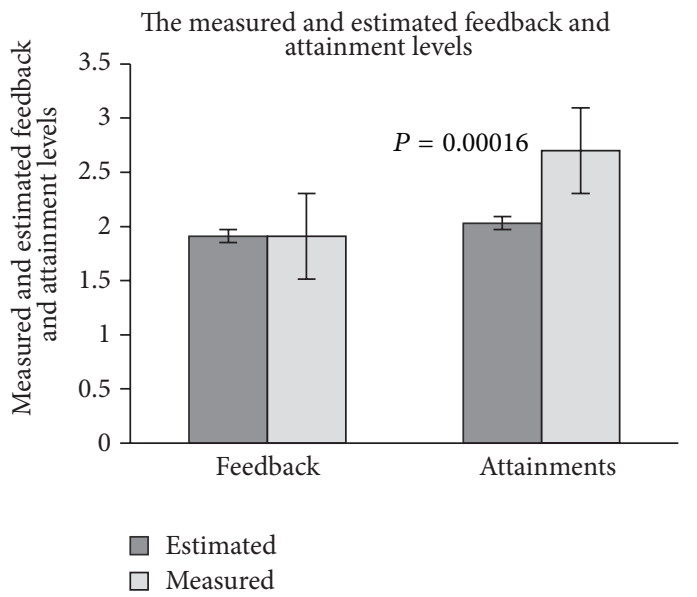

(d)

FIGURE 2: (a) shows the correlation of feedback "from pupil to teacher" and attainment level for pupils in Year 7 set 3. (b) shows the relationship between the feedback and attainment level for Group A (grey bar) and Group B (white bar) in this study. Note that there is a significant difference between the control and experimental feedback values with $P<0.05$; this is true also for the control and attainment values, with $P<0.05$ (see text for details). (c) shows the correlation between the measured and estimated attainment values. (d) compares the measured and estimated feedback and attainment values. Note that there is a significant difference between the measured and estimated attainment values, but not so for the measured and estimated feedback values (see text for details).

participants in Group B with the highest feedback levels also do have the lowest behaviour values. This suggests that their behaviour might be influencing their feedback capabilities, in turn their learning progress as reflected by their attainment level data (Figure 3(c), (A)). This is because their classwork effort equals that of some of those in Group A with higher attainment and feedback values (Figure 3(c), (A)). However, the correlation curve between behaviour and feedback has an absolute $|R|=0.1$ (Figure 3(c), (C)), indicating that there is no direct relationship between a pupils' ability to provide feedback and his or her behaviour. In contrast,, the correlation curve between classwork and feedback has an absolute $|R|=0.74$ (Figure 3(c), (B)), suggesting that there is a direct relationship between pupils ability to give feedback to teachers and how proactive they are with their classwork.

Furthermore, to determine whether the effect of feedback on attainment level could be influenced by gender, the SAT April and June data were classified in terms of gender and analysed as shown in Figure 4. The results show that, in this Year 7 set 3 class, boys have slightly higher mean feedback and attainment level than girls (Figure 4(a)), suggesting that in average boys frequently provide feedback to teachers as 
The correlation of the direct effect of feedback on attainment levels measured from mid-May to June in Phase II of the study

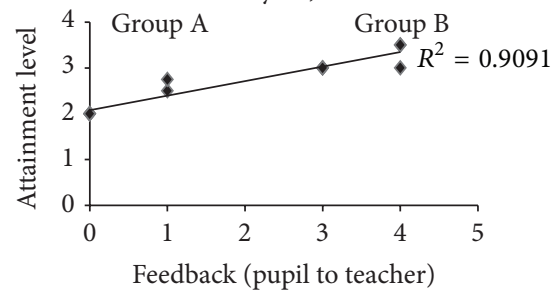

(A)

The correlation of the direct effect of feedback on attainment levels measured from mid-May to June in Phase II of the study

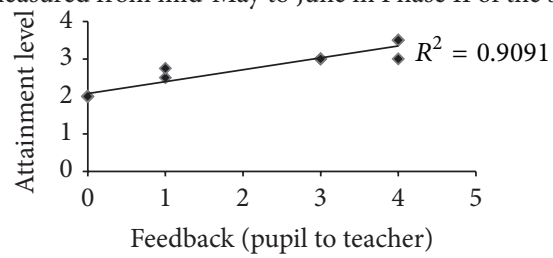

(B)

(a)

The effect of feedback from pupils to teachers on classwork and behaviour measured from mid-May to June in Phase II of the study

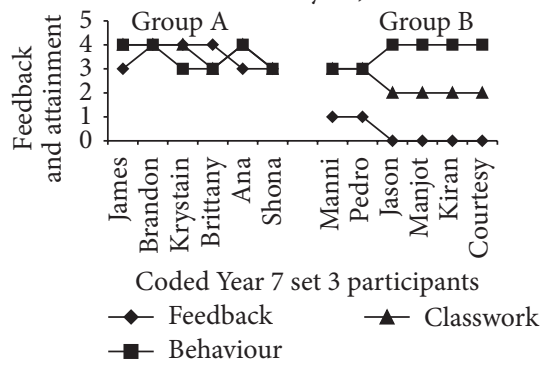

(A)

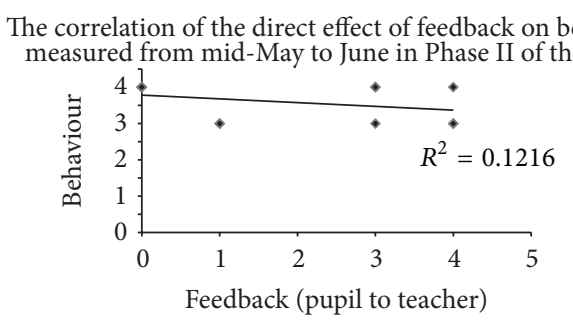

(C)

(c)

FIgURE 3: (a, A) shows the effect of feedback from pupils to teachers on attainment levels measured in mid-May in Phase II of the study. Note Group A, Group B, and the predicted grade (PG). (a, B) depicts the direct effect of feedback from pupils to teachers on the attainment levels measured in mid-May in Phase II of the study. (b, A) shows the effect of feedback from pupils to teachers on attainment levels on SAT results measured in June in Phase II of the study. (b, B) depicts the direct effect of feedback from pupils to teachers on the attainment levels on SAT results measured in June in Phase II of the study. (c, A) shows the effect of Feedback from pupils to teachers on classwork and behaviour measured from mid-May to June. (c, B) shows the correlation of the direct effect of feedback from pupils to teachers with the classwork proactiveness. (c, C) shows the correlation of the effect of feedback from pupils to teachers with behaviour.

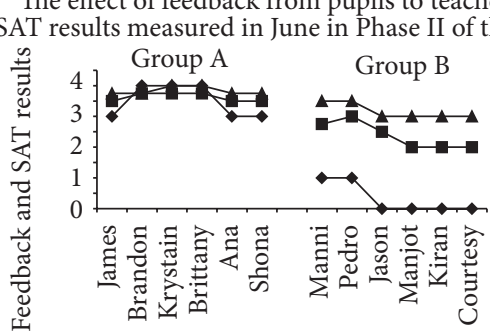

Coded Year 7 set 3 participants

$\rightarrow$ Feedback $\quad \leftarrow$ PG

$\rightarrow$ - SAT in June

(A)

The correlation of the direct effect of feedback on AT results measured in June in Phase II of the study

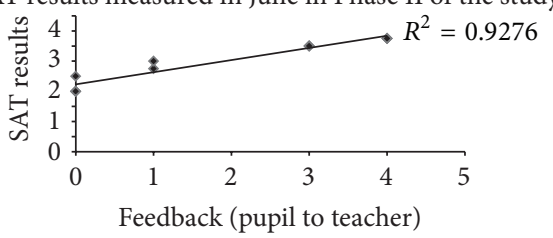

(B)

(b)

The correlation of the direct effect of feedback on classwork measured from mid-May to June in Phase II of the study

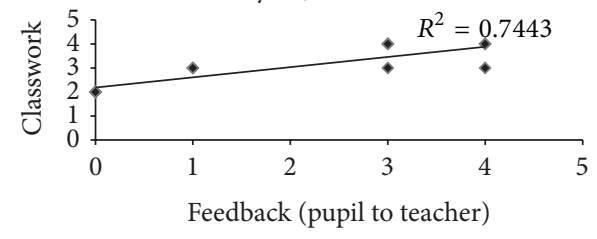

(B) 


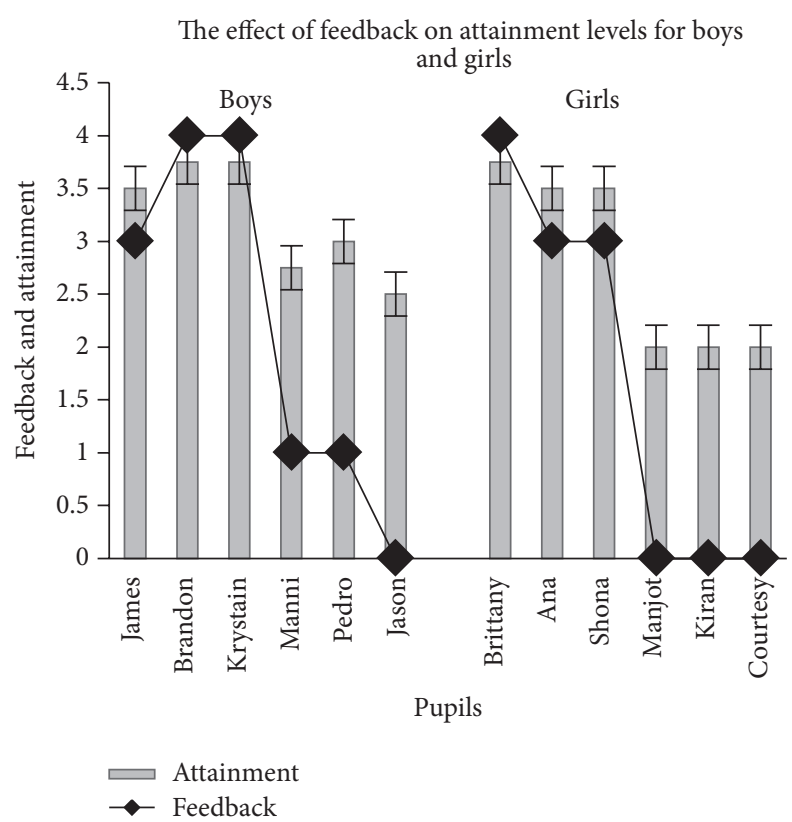

(a)

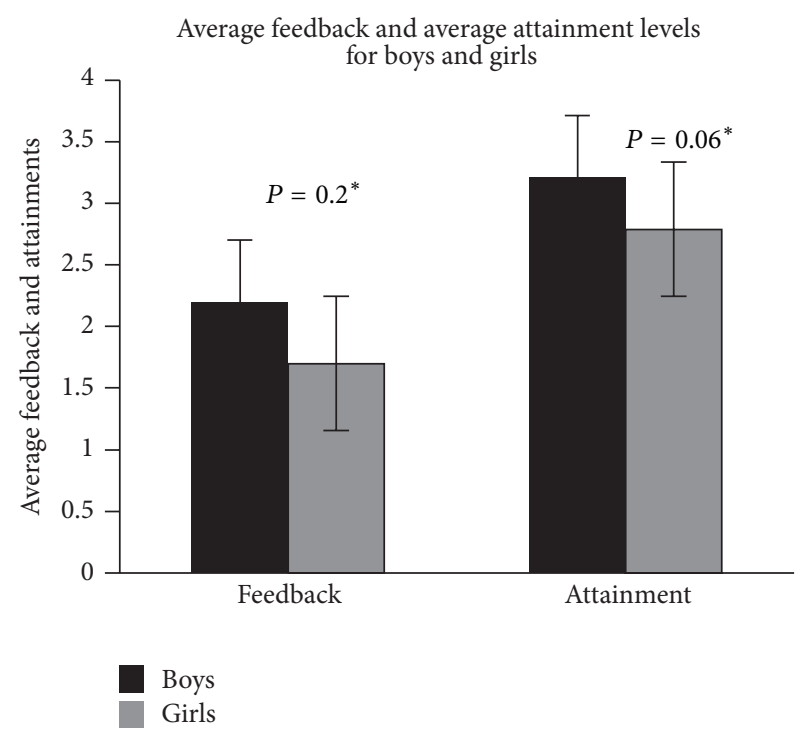

(b)

FIGURE 4: (a) shows the relationship between feedback from pupil to teacher and attainment levels for boys and girls. (b) shows the average feedback and attainment levels for both boys and girls. ${ }^{*}$ depicts that there is no significant difference between the average feedback values for boys and girls $(P<0.05)$, and this is also true for their average attainment values $(P<0.05)$. See text for details.

compared to girls in this Year 7 class (Figure 4(a)). Interestingly though, there is no statistical significance difference between the feedback value for boys and girls with $P>0.05$ (Figure 4(b)), and this is also reflected by the attainment levels of the genders with $P=0.06$ (Figure 4(b)), suggesting that the ability to provide feedback and hence accelerate learning outcomes is not gender determined. For instance, over $50 \%$ of girls in this study presented higher feedback and attainment levels, and this directly reflects their learning progress as shown in Figure 5. Consequently, by comparing the respective mean of the SAT results in April and June for all of the participants as a unit class (Figure 5(c)), a significantly high learning progress was achieved by the class with $P=0.004$ (Figure 5(b)). Interestingly, some individuals achieved higher than the class average of about $25 \%$ added value. For instance, Jason and Manni,respectively, achieved approximately twice the class average of nearly $50 \%$ added value. Importantly, they have the highest feedback values in Group B (Figure 5(a)). These results therefore seem to establish further that feedback is directly associated with learning progress.

4.3. Outcome. Taken together, these results strongly suggest that there is a profound positive regulatory effect of feedback from pupil to teacher on AfL as indicated by the attainment levels, SAT results, and classwork proactiveness in this study. The results further indicate that there is a dynamic feedback process from pupils to teachers, which does not only motivate pupils (as is the case of Manni and Pedro, Figure 5(a)), but also creates a milieu where teaching and learning becomes visible (as is the case of the high learning attainment achieved by the class between April and June, Figure 5(b)). Hence, feedback from pupils to teacher enhances visible teaching and learning, which is a novel paradigm shift from the current notion which advocates the reciprocal. For instance, this novel paradigm becomes even more apparent by simply encouraging pupils who do not frequently give feedback to start to do so, as evidenced by this simple note signed by most pupils in a Year 9 class at a state high school in Queensland, Australia:

"... Even though we had you for a short period of time, you have been one of the best science teachers I've ever had. You have taught me so much and have given me the ability to ace my test. Although we may not be able to understand your writing at times, we still managed to learn and achieve under your teaching. We will miss you so much and hope that you come back someday. Thank you for everything..."

Indeed of the 23 pupils in this class, over $70 \%$ scored ace on two occasions on their structured and summative assessment tests. This accelerated progressive learning achievement was also reflected with a Year 11 class in the same high school, where over $70 \%$ of the pupils in the class exceed their predicted target grades on their Statutory Assessment Test (SAT). As a consequence, parents and guardians were ushering positive appraisals regarding the accelerated learning progress achieved by their children in these classes.

\section{Discussion}

In this case study by using ethnographical approach as per Bourdieu and Wacquant [24], Qualis Research [25], and Schatzman and Strauss [26], the effect of feedback from 


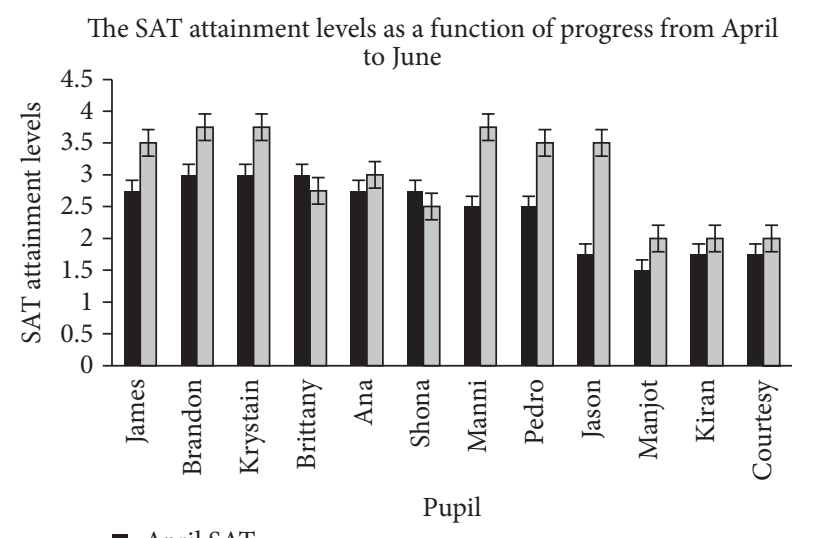

- April SAT

$\square$ June SAT

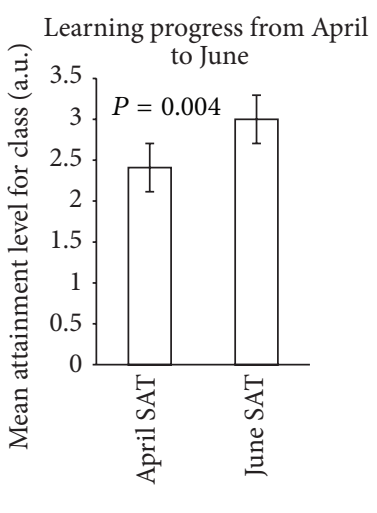

(b)

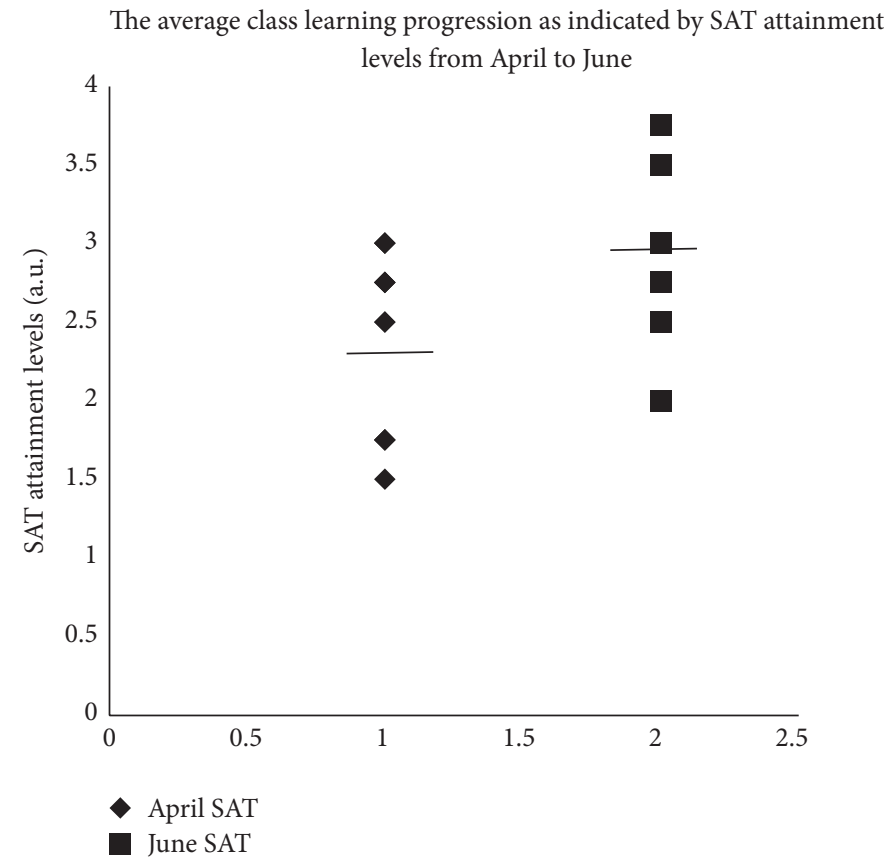

(c)

FIGURE 5: (a) Shows the progress made by individual pupil as a consequence of visible learning judged by the SAT in April and June. (b) shows the significant progress $(P=0.004)$ made by the class as a consequence of visible teaching as judged by the SAT results in April and June. (c) shows the class achievement of over $25 \%(P<0.05)$ added value between the months of April and June.

"pupil to teacher" on Assessment for Learning as indicated by the attainment levels, SAT results, classwork proactiveness, and class behaviour was evaluated. The results seem to show for the first time that attainment level and classroom proactiveness, but not behaviour, are directly regulated by feedback from pupil to teacher, and as a consequence on visible teaching and learning.

Moreover, the findings presented herein are also in accordance with the work of Hattie [8], which states that "visible teaching and learning occurs... when there is feedback given and sought by teachers and students...most evidently the student learning occur when the teachers become learners of their own teaching, and when students become their own teachers" [8, page 22]. The findings are also in agreement with Sadler [6] report which states that "feedback needs to provide information relating to the task or process of learning that fills a gap between what is understood and what is aimed to be understood, which is an aspect of visible teaching and learning."

Thus, Hattie [8] and Sadler [6] concurrences are evident in the findings presented here. For instance, Krystain who is one of three pupils in the study with the highest feedback value of 4 also has one of the highest classwork proactiveness values of 4 , as well as the highest attainment level and SAT results in April and June (Table 1, Figure 3), and as a such he was moved from Year 7 set 3 to Year 7 set 2 in June, 
thus, depicting that feedback from "pupil to teacher" enhances AfL, and this is in accordance with the Assessment Reform Group [12] findings which stated that, AfL “... is the process of seeking and interpreting evidence for use by learners and their teachers to decide where the learners are in their learning, where they need to go and how best to get there" [12].

In addition, this statement is also evidenced by Brittany, who is among those with the highest feedback values, attainment level, and SAT values (Tables 1 and 2 and Figures 1 and 3), but unlike Krystain she always reflects on her work, and as a consequence of her progressive achievements, she was moved from Year 7 set 3 to Year 7 set 2 in agreement with the Ofsted AFL Report [5], which stated that “...outstanding learning indicator is when pupils have the opportunity to reflect on their own learning..." [5]. Again this is in accordance with Hattie [8] findings which articulated that "...by reflecting on their (students) own learning... visible teaching and learning occurs ... when students become their own teachers" [8, page 22]. Thus, National Strategies [3] and DCSF [19] see the importance of feedback in AfL by ascertaining that "APP is a dynamic methodology platform and tool which should be used frequently to make inform judgements, evidenced via the feedback process about the standard of pupils' work, and so know when and where to effectively intervene to booster learner" $[3,19]$. However, there is no mention of the pupil's "voice" or account about their own learning, or how to tell the teacher where they (the pupils) are, with their understanding process. Nonetheless, the result presented in this study depicts for the very first time a pupils' friendly tool, which could be employed to determine the learning progress of pupils, downstream of the learning assessments platforms used by teaching practitioners such as AfL and APP. Thus, by measuring this dynamic feedback process, pupil may address their ability to judge and condescend when and where in their personal learning process is the right juncture and junction to provide cues via feedback to teachers, and as such the pupil's "voice" could be heard about their own learning process.

Taken together, this therefore emphasises that visible learning occurs when there is opportunity for "pupil to teacher" feedback. Interestingly, as shown in this study, the ability for a pupil to provide feedback to teachers is independent of gender or race as evidenced by Krystain and Brittany (Figure 4). Again, this is in accordance with Ofsted AfL [5], the Hattie [8] findings, and National Strategies [3], which articulated that "AfL is a natural, integral and essential part of effective learning and teaching and is a key element of personalised learning. . .teachers and children continually to reflect on how learning is progressing, see where improvements can be made and identify the next steps to take" [3]. Furthermore, the findings presented here evidenced that pupils who do not give feedback to teachers performed poorly not only in formative assessment, but also in SAT test, and as a consequence their attainment levels are among the lowest in class (Figures 1 and 3). For instance, Manjot and Jason are among those with the lowest feedback values in the study, and it is not surprising that they are also among those with the lowest attainment levels and SAT results (Figures 1 and 3 ).
Furthermore, whilst the effect of feedback on attainment levels shows that some pupils with higher feedback values exceed their predicted targets (Figure 2(b) upper panel), in contrast though, all the pupils with lower feedback values have the lowest levels of attainment, and none exceed their predicted targets (Figure 1(b), (A)). However, Pedro attainment level and SAT score are higher than Manni's even though they have the same feedback value (Figures 1 to 3). Pedro and Manni are the only two pupils in Group B with the highest feedback values; ironically they have the lowest behaviour values, suggesting that behaviour might be influencing their feedback capability, in turn their learning progress which is reflected by their lower attainment levels, given that their classwork values are equal to that of Shona and Brittany, albeit having higher attainment and feedback values (Figure 3(c), (A)).

Moreover, some pupils with higher feedback value of 4, like Britanny and Krystain, ironically do have lower behaviour value of 3 . On the other hand, James and Brandon with a lower feedback value of 3 atypically have a higher behaviour value of 4 (Figure 3(c), (A)). Furthermore, unlike Brittany who has a feedback value of 4 , and Ana with a behaviour and classroom proactiveness value of 4, Shona is the only person in that group with lower behaviour, feedback, and class proactiveness values of 3 (Figure 2(a) and Figure 3(c), (A)), which suggests that an improvement of class proactiveness could ameliorate progressive learning. This therefore indicates that there might be alternative intrinsic factor that might be regulating attainment other than feedback from pupils to teachers. Indeed, according to Boaler [10] and Hattie [8], there are other factors that could regulate learning, of which the teacher and curricula are among the highest contributors.

This research finding therefore articulates feedback from "pupil to teacher" as a paradigm shift from the classical paradigm of feedback from "teacher to pupil." In this new paradigm, therefore, the emphasis is geared towards pupils understanding of objectives build from previous knowledge. These are then feedback onto the teachers by the pupils, in the form of discrete loops of cues and questions, where 'what stage or level' they (the pupils) are with their learning,' therefore enabling them (the pupils) to move to the next level of understanding, and thus acquired as in this study (mathematical/science/chemistry) independence, which in turn is reflected by their success in both formative and summative assessments. Interestingly, Claxton [28] stated that "... activities can be very interesting and engaging. ..unless they are stretch. . .the system. ..pushes it near its limits. .." [28, page 29]. Taken together, this therefore depicts that relevant feedback from pupil to teacher, and befitting pedagogy, will always extend pupils learning and hence progress, as judged by the simple note from the Year 9 pupils at the state high school in Queensland.

\section{Conclusion}

The data presented herein vehemently evidenced a profound positive regulatory effect of feedback from "pupils to teachers" on (Assessment for Learning) AfL as indicated by the 
attainment levels, (Statutory Assessment Test) SAT results, and classwork proactiveness. This evidence shows for the first time that, when feedback from "pupil to teacher" is used in combination with "teacher to pupil" feedback, AfL is ameliorated and hence visible and accelerated learning occurs in a neither gender nor subject nondependent manner, consequently, heralding a pupils' friendly tool that could be employed to determine the learning progress of pupils downstream of the conventional assessments platforms. This is because, as we have shown in the data presented herein, we can now quantify "pupil to teacher" feedback. Given that, irrespective of gender, feedback from pupil to teacher tends to parallel attainment level and learning achievement.

Interestingly, the study shows that, on average, boys frequently provide feedback to teachers as compared to girls. It nonetheless also shows that the combination of other determinants like classwork proactiveness, reflection, and behaviour may interfere with the net ability to provide feedback and hence progressive learning achievement. For instance, Krystain, a boy with one of the highest feedback values, also has one of the highest classwork proactiveness, attainment level, and SAT results, albeit a lower behaviour value; nonetheless he was moved on to a higher tier.

On the other hand, Brittany, a girl who is like Krystain, is among those with the highest feedback values which also parallels the attainment and SAT values, but unlike Krystain, she always reflects on her work, and as a consequence of her progressive achievements, she was moved on to a higher tier as Krystain. Taken together, this therefore indicates that pupil to teacher feedback could be associated with accelerated learning in a gender nondependent manner, and as such may be considered as a key upstream regulator of visible learning.

Consequently, this study seems to indicate that pupil to teacher feedback is geared towards pupils understanding of objectives built from previous knowledge. These are then feedback to teachers by pupils in the form of discrete loops of cues and questions, at what level or stage they are at with their learning, therefore enabling them (the pupils) to move to the next level of understanding, and thus acquired subject nondependent independence. This in turn is reflected by their success in both formative and summative assessments, and when this is used in combination with feedback from "teacher to pupil," visible teaching and learning occurs, as the pupil progresses to higher academic tiers. This therefore indicates that relevant feedback from "pupil to teacher," and befitting pedagogy will always extend learning and hence progress, as judged by the simple note from the Year 9 pupils at the state high school in Queensland, and their parent's positive appraisals to this state high school, regarding the accelerated learning progress achieved by their children.

Taken together, it is imperative therefore that pupils who do not ask questions or are proactive in class should be encouraged to do so, given that this and other recent studies have evidenced that, besides the conventional paradigm of feedback from "teacher to pupil," there is however a novel prevailing paradigm which currently is overwhelmingly showing the importance and benefits of "pupil to teacher" feedback in teaching and learning. Hence, it would therefore be important for the necessary authorities to promote further research on this topic, given that such dynamic feedback process from pupil to teacher does not only motivate and boost pupils confidence, but also creates an environment where teaching and learning becomes visible, with profound financial and educational implications on standards, achievements, equality, behavioural, and classroom managements in schools.

\section{Limitations}

One of the penultimate limitations of this work is the measurement of abstract variables like feedback, class behaviour, and classwork proactiveness. Indeed, these are very difficult concepts to be accurately measured and reproduced with minimum error. Another limiting factor is the background, belief, and disposition of the participating pupils which were not taken into account.

\section{Further Study}

To improve on the findings, further cross-curricula study not only for maths needs to be carried out over a longer duration-for at least an entire academic year, simultaneously in several different schools using larger population sizes, whilst taking into consideration all the other cofounders like pupil's background, belief, homes, and disposition. A more accurate way to measurement abstract concepts and variables like feedback, behaviour, and class work proactiveness would be critical for any future study of this sort.

\section{Abbreviations}

AfL: Assessment for learning

APP: Assessing of pupils progress

Ofsted: Office for standards in education

DfES: Department for education and skills.

\section{Consent}

School in England. Ethical approval was obtained from the school in England authorities, and as such adhered to the school confidentiality clauses and the school rules and regulations. Permission was granted by the school authorities for the principal researcher to be embedded in the school to carry out the research. This enabled the researcher to establish trust and gain respect with both staff and pupils during the research period and crucially to assist in recruiting all the targeted participants. School in Australia. Although no direct or indirect research was carried out in the school in Australia, nevertheless, pupils taught by the principal researcher, in any of the classes mentioned herein, have not been identified but were kept anonymous.

\section{Conflict of Interests}

The authors declare that there is no conflict of interests regarding the publication of this paper. 


\section{Acknowledgments}

The authors would like to thank Brian Nash for his professional insight about teaching and learning in England, UK, and his immerse contributions to areas of Assessment for Learning (AfL) and Assessing Pupils' Progress (APP). The authors would also like to acknowledge the tireless effort of Lee Jerome from London Metropolitan University, without whom this project would not have commenced. The authors would like to thank Trevor Newman and Matthew Allen for their professional insight about teaching and learning in Queensland, Australia.

\section{References}

[1] H. M. G. Watt, "Attitudes to the use of alternative assessment methods in mathematics: a study with secondary mathematics teachers in Sydney, Australia," Educational Studies in Mathematics, vol. 58, no. 1, pp. 21-44, 2005.

[2] J. Biggs, "Enhancing teaching through constructive alignment," Higher Education, vol. 32, no. 3, pp. 347-364, 1996.

[3] National Strategies AFL, 2008, http://www.standards.dcsf.gov .uk/nationalstrategies/assessment/assessmentforlearningafl.

[4] "National Centre for Excellence in the Teaching of Mathematics (NCETM)," 2008, http://www.ncetm.org.uk .

[5] "Office for standards in Education (Ofsted) Assessment for learning: the impact of National Strategy support," 2008, http://www.ofted.gov.uk .

[6] D. R. Sadler, "Formative assessment and the design of instructional systems," Instructional Science, vol. 18, no. 2, pp. 119-144, 1989.

[7] D. L. Meyer, "The poverty of constructivism," Educational Philosophy and Theory, vol. 41, no. 3, pp. 332-341, 2009.

[8] J. Hattie, Visible Learning: A Synthesis of Over 800 Meta-Analyses Relating to Achievement, Routledge, Oxon, Md, USA, 2009.

[9] Educational Research, http://EzineArticles.com/1857834 .

[10] J. Boaler, "Mathematical modeling and new theories of learning," Teaching Mathematics and Its Applications, vol. 20, pp. 121127, 2002.

[11] J. Ryan and J. Williams, Mathematical Discussions with Children: Exploring Methods and Misconceptions as a Strategy, University of Manchester, 2000.

[12] Assessment Reform Group, 2002, http://www.assessmentreform-group.org.

[13] D. Porcaro, "Applying constructivism in instructivist learning cultures," Multicultural Education \& Technology Journal, vol. 5, pp. 39-54, 2011.

[14] "Department for Education and Skills (DfES)," 2008, http://www.standards.dfes.gov.uk/secondary .

[15] J. Piaget, “The Psychology of Intelligence. New York: Routledge. Qualification and Curriculum Authority," 1950, http://www.qca .org.uk/curriculum .

[16] R. DeVries, Developing Constructivist Early Childhood Curriculum: Practical Principles and Activities, Teachers College Press, New York, NY, USA, 2002.

[17] Assessment Reform Group, 2012, http://www.aaia.org.uk/afl/ assessment-reform-group.

[18] Ofsted Report, 2009, http://www.ofsted.gov.uk/oxedu_reports/ display/(id)/114253.
[19] "Department for Children Schools and Families (DCSF) Getting with Grip with APP," 2009, http://www.teachernet.gov.uk/ publications.

[20] National Strategies AFL, 2008, "The associated reference on the reference list remains the same," http://www.standards.dcsf.gov .uk/nationalstrategies/assessment/assessmentforlearningafl.

[21] Australian Curriculum, Assessment and Reporting Authority (ACARA), 2012, http://www.acara.edu.au/curriculum .

[22] J. Piaget, Logique Et Connaissance Scientifique, Encyclopédie de La Pléiade, 1967.

[23] The Cockcroft Report, "Mathematics counts," Report of the Committee of Inquiry into the Teaching of Mathematics in Schools Under the Chairmanship of Dr WH Cockcroft, Her Majesty's Stationery Office, London, UK, 1982.

[24] P. Bourdieu and L. Wacquant, An Invitation to Reflexive Sociology, The University of Chicago, Chicago, Ill, USA, 1992.

[25] Qualis Research, 2008, http://whttp://www.qualisresearch.com.

[26] L. Schatzman and A. Strauss, Field Research: Strategies for a Natural Sociology, Prentice-Hall, Englewood Cliffs, NJ, USA, 1973.

[27] "Department for Education and Skills (DfES)," 2013, http:// www.education.gov.uk/schools/teachingandlearning/curriculum/secondary/b00199003/mathematics/ks3/attainment/ processes.

[28] G. Claxton, "Mathematics and the mind gym: hoe subject teaching develops a learning mentally," For the Learning of Mathematics, vol. 24, pp. 27-30, 2004. 

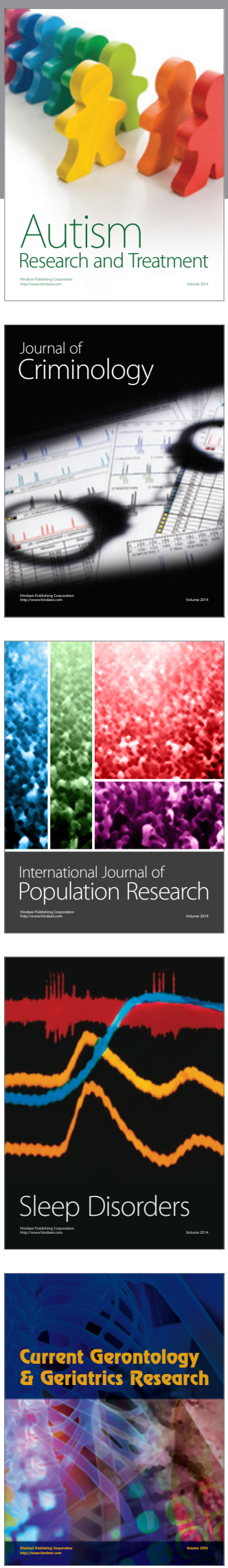
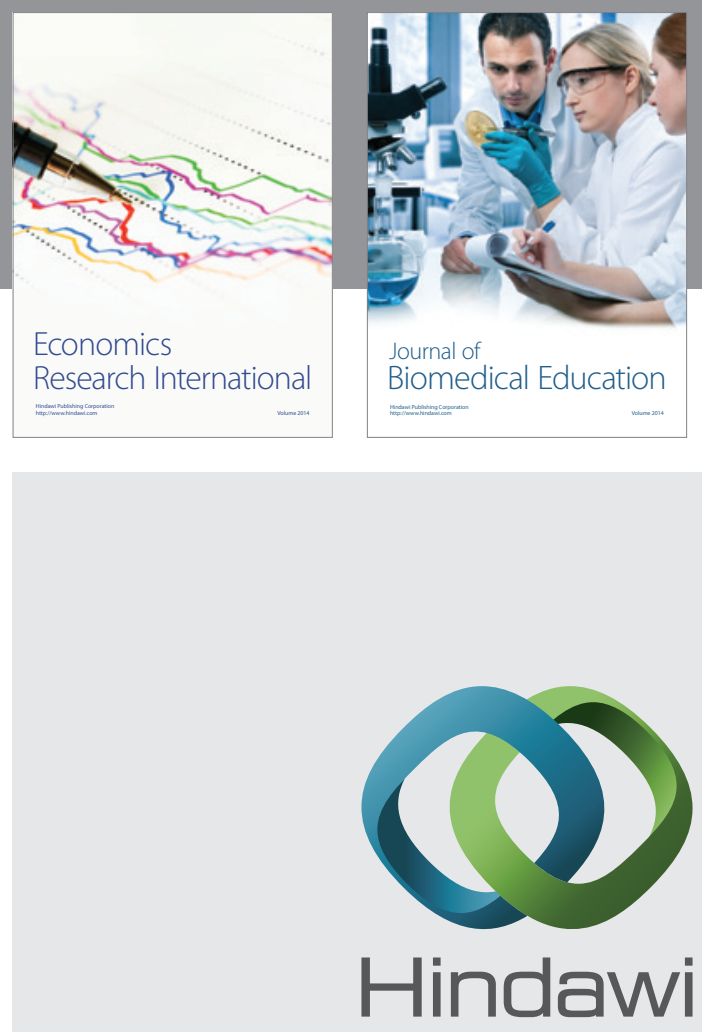

Submit your manuscripts at

http://www.hindawi.com
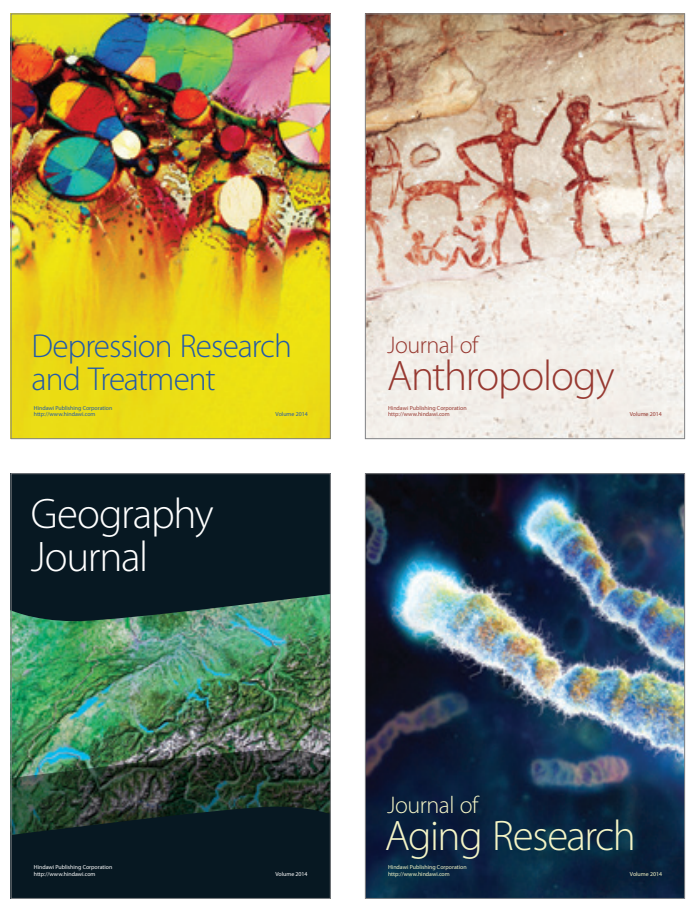
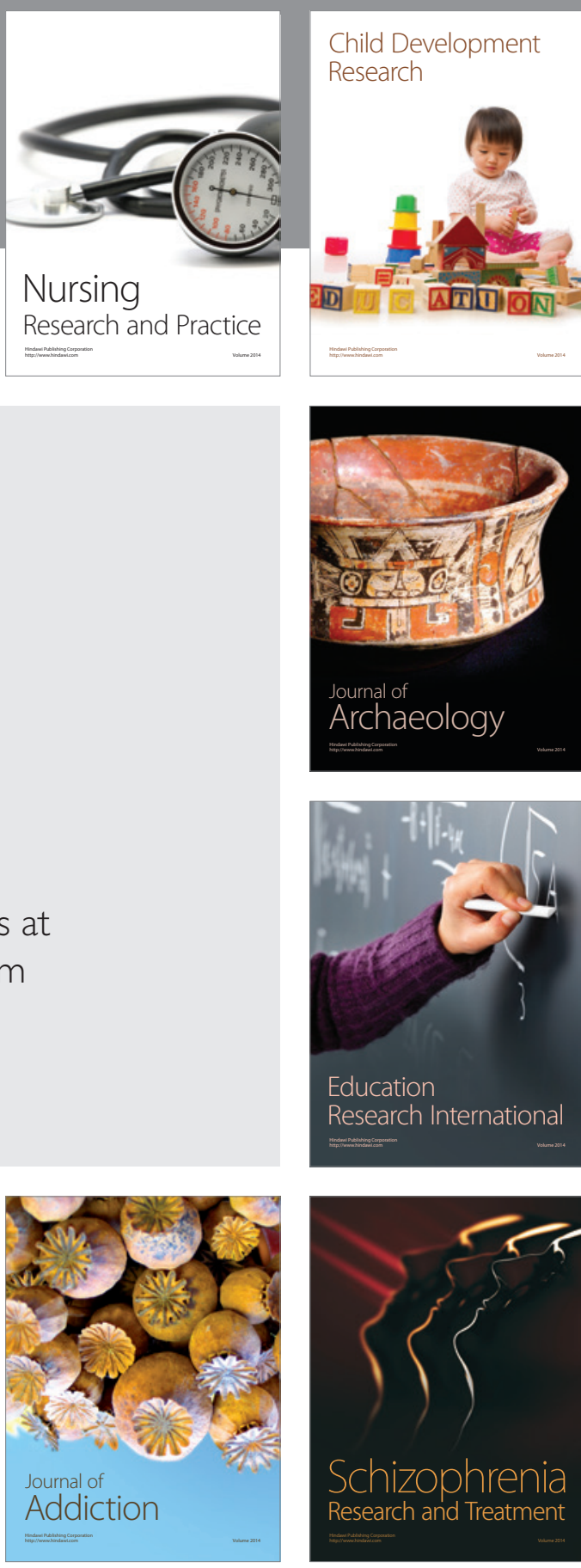

(D)
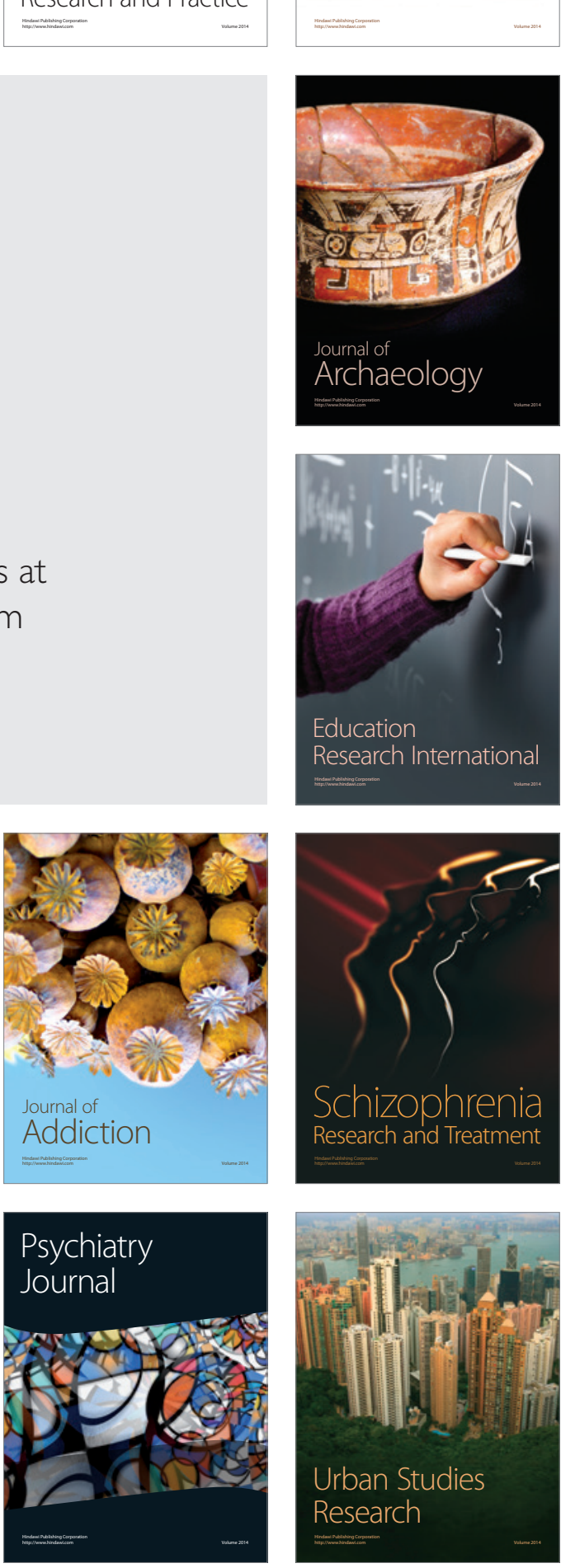